\title{
Comparison of adiponectin levels and some metabolic parameters in dairy cows with subclinical and clinical ketosis")
}

\author{
GULSAH AKGUL, ZAFER MECITOGLU*, DUYGU UDUM KUCUKSEN**, SEZGIN SENTURK* \\ Deparment of Internal Medicine, Faculty of Veterinary Medicine, Siirt University, Siirt, Turkey \\ *Deparment of Internal Medicine, **Deparment of Biochemistry, Faculty of Veterinary Medicine, \\ Uludağ University, Bursa, Turkey
}

Akgul G., Mecitoglu Z., Udum Kucuksen D., Senturk S.

Comparison of adiponectin levels and some metabolic parameters

in dairy cows with subclinical and clinical ketosis

Summary

The aim of the presented study was to evaluate the relationship between adiponectin and the non-esterified fatty acids (NEFA), $\beta$-hydroxybutyric acid (BHBA), glucose, albumin, gamma-glutamyl transferase (GGT), calcium, phosphorus and blood urea nitrogen (BUN) levels in healthy cows and cows suffering clinical or subclinical ketosis in the early postpartum period. A total of $\mathbf{4 5}$ Holstein-Friesian dairy cows, consisting of 15 with clinical ketosis, 15 with subclinical ketosis and 15 healthy controls, was used in the study. The selection of animals was based on blood BHBA levels and urine ketone strip results on day 7 after parturition. Blood adiponectin, NEFA, glucose, albumin, GGT, calcium, phosphorus and BUN were also measured on day 7 postpartum. Adiponectin levels were significantly lower in both clinical ketosis and subclinical ketosis groups compared to the control group. NEFA levels were higher and glucose and calcium levels were lower in both ketosis groups when compared to the control animals. On the other hand, blood albumin, GGT, phosphorus and BUN levels did not differ among study groups. Based on the results of the study, it can be stated that adiponectin may play a role in the pathogenesis of ketosis. This role could be a lower milk yield and better energy balance in early postpartum dairy cows with high adiponectin levels due to increased whole body tissue insulin sensitivity.

Keywords: adiponectin, $\beta$-hydroxybutyric acid, NEFA, ketosis

The transition period that starts three weeks before and ends three weeks after parturition is characterized by sudden metabolic and physiologic changes (7). In this short time period, the pregnancy and lactational status of the cow shift, which causes severe stress. Dry matter intake (DMI) starts to decline before parturition, reaches the lowest point around parturition and steadily increases for the next six to eight weeks after delivery (7). The mammary glands of fresh postpartum cattle use about $97 \%$ of the energy and $83 \%$ of the protein from feed intake for milk production (4). However, cows' requirements for milk production are high in the period during which DMI is still low. Thus, these increased demands of the mammary glands are fulfilled by whole body insulin resistance excluding the mammary glands (8), which is also one of the significant

1) This study was financially supported by the Research Fund of Uludag University (Grant no. KUAP(V)-2012/46). metabolic changes occurring in this transition period. As a result of decreased DMI, high-yielding dairy cattle experience varying degrees of negative energy balance (NEB), increased energy requirements for milk production and insulin resistance in the early postpartum period. The cows' metabolisms struggle with NEB by stimulating lipolysis of adipose tissue, which results in an increase in blood levels of non-esterified fatty acids (NEFA). Fatty liver and ketosis are the main energy metabolism-related disorders of transition cows.

Elevated blood NEFA and BHBA levels are the main indicators of NEB in dairy cattle. Along with NEFA and BHBA, glucose, albumin, Gamma-Glutamyl Transferase (GGT) and Blood Urea Nitrogen (BUN) levels are also taken into consideration when performing a metabolic profile test for evaluating a herd's NEB, ketosis and fatty liver status. Blood glucose levels are generally decreased in ketotic cows; however, due to 
decreased insulin sensitivity, increased blood glucose levels could also be detected in cows with fatty liver and ketosis $(21,26)$. Blood albumin and BUN levels are negatively correlated with the degree of hepatic fat infiltration (20). On the other hand, blood GGT levels are demonstrated to be positively correlated with levels of hepatic lipidosis (2).

Ketosis and calcium metabolism are in a relationship that directly affect each other. In general, hypocalcemia may be shaped at varying degrees in the animals with ketosis. Although ionized calcium due to metabolic acidosis at varying degrees in ketosis is usually normal, a decrease in total calcium concentration also needs attention (18).

Adiponectin is a hormone secreted from adipose tissue which regulates energy metabolism by increasing insulin sensitivity of tissues and stimulating glucose utilization and fatty acid oxidation by activating AMP-activated protein kinase $(29,30)$. Circulating levels of adiponectin are low around parturition, which is associated with decreased insulin sensitivity in that period $(15,23)$.

The aim of the presented study was to evaluate the relationship between adiponectin and blood NEFA, BHBA, glucose, albumin, GGT, calcium, phosphorus and BUN levels in healthy cows and cows suffering clinical or subclinical ketosis.

\section{Material and methods}

Animals and sample collection. The study was conducted on a single farm. Selection of animals was made according to blood BHBA levels and urine ketone strip results on day 7 after parturition. Fifteen animals with ketonuria and with blood BHBA levels higher than $1.4 \mathrm{mmol} / \mathrm{l}$ were enrolled in the study as the Clinical Ketosis Group (CKG). Another 15 cows without ketonuria and with blood BHBA levels between 1 and $1.4 \mathrm{mmol} / \mathrm{l}$ were enrolled as the Subclinical Ketosis group (SKG). Fifteen cows without ketonuria and with blood BHBA levels lower than $1 \mathrm{mmol} / 1$ were enrolled as the Control Group (CG). Animals selected for the study were clinially examined for postpartum diseases such as mastitis, metritis, displaced abomasum and laminitis; those detected to be suffering from any one of these diseases were excluded from the study and new ones were enrolled. At the end, 45 Holstein-Friesian dairy cattle between the ages of 3-6 years (mean $4.2 \pm 0.4$ ) were selected for the study. Housing, feeding and management conditions were the same for all cows. Diets were formulated according to recommendations by the NRC (16) and delivered as a total mix ration. All cows were housed in free stall barns.

Blood samples for NEFA and glucose analysis were collected before morning feeding. Blood BHBA levels increase after feeding, thus it is suggested (15) for blood samples to be collected $4-5 \mathrm{~h}$ after feeding in order to determine peak concentrations of BHBA. Therefore, blood samples for BHBA albumin, GGT, calcium, phosphorus and BUN were collected 4-5 $\mathrm{h}$ after morning feeding between 11:00 and 12:00 a.m., from the coccigeal vein into plain tubes. After clotting, the samples were centrifuged at 1000 r.p.m. for $15 \mathrm{~min}$ and sera were immediately separated and stored at $-20^{\circ} \mathrm{C}$ until analyses.

Biochemical analysis. Serum glucose, albumin, calcium, phosphorus, GGT and BUN levels were measured by using an automatic analyser (Roche Cobas Integra 400; Roche Diagnostics, Indianapolis, IN). Serum NEFA(Bovine NEFA ELISA No: CK-E90284, Eastbiopharm, China), BHBA (Bovine BHBA ELISA No: CK-E90438, Eastbiopharm, China) and adiponectin (Bovine adiponectin (ADP) ELISA No: E90440, Eastbiopharm, China) levels were measured according to the manufacturer's instructions by using commercial ELISA kits.

Statistical analysis. Statistical analysis of the results was performed by using SigmaPlot 12 software (Systat Software Inc., USA). A normality test was performed using the Shapiro-Wilk test, and the data were found to be normally distributed. Serum adiponectin, NEFA, BHBA, glucose, albumin, calcium, phosphorus, GGT and BUN levels samong groups were compared using repeated measures analysis of variance (RM ANOVA). The relationships between the measured parameters were quantified by Pearson's correlation coefficients. For all analyses, $\mathrm{P} \leq 0.05$ was considered significant.

\section{Results and discussion}

Adiponectin levels were lower $(p<0.001)$ in CKG and SKG compared to CG. As the animal selection criteria were based on blood BHBA levels, BHBA levels were different $(p<0.001)$ among groups. NEFA levels were higher and glucose and calcium levels were lower in both ketosis groups compared to the control animals (Tab.1). On the other hand, blood albumin, GGT, phosphorus and BUN levels did not differ among study groups.

Tab. 1. Serum biochemical values of the animals incorporated into the scope of the study $($ mean $\pm S E ; n=15)$

\begin{tabular}{|l|c|c|c|c|}
\hline \multicolumn{1}{|c|}{$\begin{array}{c}\text { Biochemical } \\
\text { parameters }\end{array}$} & CKG & SKG & CG & $\begin{array}{c}\text { Group of animal } \\
\text { Ranges }\end{array}$ \\
\hline Adiponectin (ng/ml) & $12.9 \pm 0.3^{\mathrm{A}}$ & $14.7 \pm 1.2^{\mathrm{A}}$ & $21.2 \pm 1.4^{\mathrm{B}}$ & - \\
\hline BHBA (mmol/L) & $2.2 \pm 0.02^{\mathrm{A}}$ & $1.1 \pm 0.01^{\mathrm{B}}$ & $0.02 \pm 0.001^{\mathrm{C}}$ & $0-1.2$ \\
\hline NEFA (mmol/L) & $0.3 \pm 0.04^{\mathrm{A}}$ & $0.2 \pm 0.04^{\mathrm{A}}$ & $0.09 \pm 0.002^{\mathrm{B}}$ & $<0.6$ \\
\hline Glucose (mg/dL) & $47.7 \pm 1.9^{\mathrm{A}}$ & $52.9 \pm 1.7^{\mathrm{A}}$ & $68.9 \pm 2.5^{\mathrm{B}}$ & $45-75$ \\
Albumin (g/dL) & $3.3 \pm 0.09^{\mathrm{A}}$ & $3.3 \pm 0.1^{\mathrm{A}}$ & $3.2 \pm 0.1^{\mathrm{A}}$ & $3.0-3.5$ \\
GGT (IU/L) & $23.3 \pm 2.3^{\mathrm{A}}$ & $24.4 \pm 2.2^{\mathrm{A}}$ & $19.9 \pm 1.3^{\mathrm{A}}$ & $6.1-24$ \\
Calcium (mg/dL) & $8.7 \pm 0.2^{\mathrm{A}}$ & $9.0 \pm 0.1^{\mathrm{A}}$ & $9.8 \pm 0.1^{\mathrm{B}}$ & $8.3-1.2$ \\
\hline Phosphorus (mg/dL) & $6.2 \pm 0.3^{\mathrm{A}}$ & $6.1 \pm 0.1^{\mathrm{A}}$ & $6.1 \pm 0.1^{\mathrm{A}}$ & $4.5-6.5$ \\
\hline BUN (mg/dL) & $11.6 \pm 0.8^{\mathrm{A}}$ & $11.5 \pm 0.8^{\mathrm{A}}$ & $13.5 \pm 0.8^{\mathrm{A}}$ & $6-27$ \\
\hline
\end{tabular}

Explanation: A, B, C - the values followed by the different letter show statistically significant differences at $\mathrm{p}<0.001$ 
Correlation coefficients and significance levels between measured parameters are given in Table 2. BHBA and adiponectin levels were positively correlated in CG. However, correlation between the same parameters was negative when data was pooled. GGT and BUN levels were negatively correlated in $\mathrm{CG}$ and $\mathrm{CKG}$ groups. The highest correlation between measured parameters was detected in pooled data, as expected, due to a greater volume of data evaluated. NEFA was negatively and glucose positively correlated with adiponectin. Calcium was positively correlated with adiponectin and glucose; however, the correlation between calcium and NEFA and calcium and BHBA was negative.

A negative energy balance and consequent ketosis is one of the main health problems in dairy herds. The incidence of the disease is expected to rise parallel to the selection of cows solely based on milk and milk fat production. Thus elucidating the metabolic pathways of ketosis would be a step toward future treatment and prevention protocols.

Ketosis could be defined simply as an increase in the circulating levels of ketone bodies. BHBA is the most stable ketone body, thus detection diagnosis of ketosis is based on blood BHBA levels. Different thresholds of BHBA are used for the detection of ketosis in dairy cows $(6,10$, 18). Walsh et al. (27) reported that BHBA levels higher than $1 \mathrm{mmol} / \mathrm{l}$ in the first week and higher than $1.4 \mathrm{mmol} / \mathrm{l}$ in the second week of lactation are associated with decreased reproductive performance. Similarly Ospina et al. (18) reported that cows with BHBA levels higher than $1 \mathrm{mmol} / 1$ in the first two weeks of lactation are 6.9 and 2.3 times more likely to suffer from displaced abomasum and metritis, respectively. Thus in the present study we acquired the threshold levels of 1 and $1.4 \mathrm{mmol} / \mathrm{l}$ for the detection of subclinical ketosis
Tab. 2. Correlations between serum adiponectin, NEFA, BHBA, glucose, albumin, BUN, GGT, Ca and P levels in control group (CG), subclinical ketosis group (SKG), clinical ketosis group (CKG) and pooled data

\begin{tabular}{|c|c|c|c|c|c|c|c|c|}
\hline$C G(n=15)$ & NEFA & BHBA & Glucose & Albumin & BUN & GGT & $\mathrm{Ca}$ & $\mathbf{P}$ \\
\hline Adiponectin & 0.40 & $0.60^{*}$ & -0.14 & 0.19 & -0.04 & -0.39 & 0.48 & 0.23 \\
\hline NEFA & & 0.18 & -0.06 & 0.39 & 0.21 & -0.38 & 0.21 & 0.15 \\
\hline BHBA & & & -0.09 & 0.10 & -0.21 & -0.51 & 0.32 & 0.40 \\
\hline Glucose & & & & -0.06 & -0.15 & 0.14 & 0.28 & -0.13 \\
\hline Albumin & & & & & 0.52 & $-0.55^{*}$ & 0.48 & 0.45 \\
\hline BUN & & & & & & 0.14 & 0.27 & 0.32 \\
\hline GGT & & & & & & & -0.45 & -0.39 \\
\hline $\mathrm{Ca}$ & & & & & & & & 0.07 \\
\hline SKG $(n=15)$ & NEFA & BHBA & Glucose & Albumin & BUN & GGT & $\mathrm{Ca}$ & $\mathbf{P}$ \\
\hline Adiponectin & -0.31 & 0.09 & 0.07 & 0.40 & -0.04 & 0.16 & -0.15 & -0.18 \\
\hline NEFA & & 0.08 & -0.22 & -0.33 & -0.15 & 0.30 & -0.26 & 0.23 \\
\hline BHBA & & & 0.31 & 0.43 & 0.37 & -0.17 & 0.37 & 0.41 \\
\hline Glucose & & & & 0.07 & 0.10 & -0.34 & 0.15 & 0.29 \\
\hline Albumin & & & & & 0.37 & -0.38 & $0.55^{*}$ & $0.64^{*}$ \\
\hline BUN & & & & & & -0.43 & 0.69 ** & 0.36 \\
\hline GGT & & & & & & & -0.31 & -0.27 \\
\hline $\mathrm{Ca}$ & & & & & & & & $0.55^{*}$ \\
\hline CKG $(n=15)$ & NEFA & BHBA & Glucose & Albumin & BUN & GGT & $\mathrm{Ca}$ & $\mathbf{P}$ \\
\hline Adiponectin & -0.03 & 0.13 & 0.04 & -0.36 & 0.31 & $0.72^{* *}$ & -0.12 & -0.01 \\
\hline NEFA & & 0.13 & -0.47 & $0.56^{*}$ & 0.30 & -0.15 & -0.17 & 0.22 \\
\hline BHBA & & & -0.02 & 0.22 & 0.35 & 0.13 & -0.17 & -0.20 \\
\hline Glucose & & & & -0.21 & -0.26 & 0.20 & 0.19 & -0.20 \\
\hline Albumin & & & & & 0.29 & $-0.61^{*}$ & 0.09 & 0.33 \\
\hline BUN & & & & & & -0.01 & -0.13 & 0.42 \\
\hline GGT & & & & & & & -0.03 & -0.41 \\
\hline $\mathrm{Ca}$ & & & & & & & & -0.51 \\
\hline $\begin{array}{l}\text { Pooled Data } \\
\qquad(\mathrm{n}=45)\end{array}$ & NEFA & BHBA & Glucose & Albumin & BUN & GGT & $\mathrm{Ca}$ & $\mathbf{P}$ \\
\hline Adiponectin & $-0.45^{* *}$ & $-0.60^{* *}$ & $0.50^{* *}$ & 0.06 & 0.26 & -0.09 & $0.40^{* *}$ & 0.01 \\
\hline NEFA & & $0.52^{* *}$ & $-0.56^{* *}$ & 0.11 & -0.19 & 0.16 & $-0.42^{* *}$ & 0.17 \\
\hline BHBA & & & $-0.65^{* *}$ & 0.09 & $-0.36^{*}$ & 0.14 & $-0.50^{* *}$ & 0.06 \\
\hline Glucose & & & & -0.12 & 0.24 & -0.18 & 0.50 ** & -0.07 \\
\hline Albumin & & & & & $0.33^{*}$ & $-0.44^{* *}$ & 0.15 & $0.39 *$ \\
\hline BUN & & & & & & -0.21 & 0.25 & 0.29 \\
\hline GGT & & & & & & & -0.23 & $-0.35^{\star}$ \\
\hline $\mathrm{Ca}$ & & & & & & & & -0.27 \\
\hline
\end{tabular}

Explanations: asterisks indicate significant correlation between parameters $(* \mathrm{P}<0.05, * * \mathrm{P}<$ 0.01). (NEFA - non-esterified fatty acid, BHBA - $\beta$-hydroxy butyric acid, BUN - blood urea nitrogen, GGT - Gamma-Glutamyl Transferase, $\mathrm{Ca}$ - calcium, $\mathrm{P}$ - phosphorus)

and animals with blood BHBA levels higher than 1.4 $\mathrm{mmol} / \mathrm{l}$ were enrolled in the study as clinical ketosis, respectively. Adiponectin is an adipokine secreted mainly from adipose tissue, which is resposible mainly for glucose homeostasis by increasing insulin sensitivity. Kabara et al. (12) reported that along with roles in the energy metabolism of cattle, adiponectin also plays a role in inflamatory responses by decreasing 
the tumor necrosis factor- $\alpha$ (TNF- $\alpha$ ) expression by macrophages. Decreased tissue insulin resistance in the early postpartum period is an important metabolic adaptation resulting from the mobilization of blood glucose to mammary glands $(11,14)$. Thus, high adiponectin levels in the early postpartum period will result in a lower milk yield and better energy balance. Konstatinos (13) reported that the milk yield of cows with higher circulating adiponectin in the postpartum period was lower when compared to cows with lower adiponectin levels. NEFA levels were not correlated with adiponectin in that study. However, we detected a negative correlation between adiponectin and NEFA. That finding is compatible with other studies $(12,23)$ conducted on early postpartum dairy cows.

Adiponectin reachs its nadir in the first week after parturition in cattle and steadily increases to its peak for six to eight weeks after parturition $(15,17)$. As adiponectin plays important metabolic roles like increasing insulin sensitivity and decreasing lipomobilization, low levels of adiponectin could result in disrupted energy metabolism in the early postpartum period of dairy cows (15). The cows used in our study were within the first week of lactation, the time period in which adiponectin levels are expected to be lowest, thus lower adiponectin levels in cows suffering clinical or subclinical ketosis when compared to healthy ones in the presented study could be attributed to halted energy metabolism and the role of adiponectin in pathogenesis of ketosis.

BHBA and NEFA levels were negatively correlated with blood glucose, which is an expected finding, as the lipomobilisation is triggered by low blood glucose levels (15). Glucose levels were higher in healthy cows when compared to ketotic ones and positively correlated with adiponectin levels in pooled data; however, a similar correlation was not detected within groups. Ohtani et al. (17) found a non-significant negative correlation between glucose and adiponectin. Similarly, Konstantinos (13) reported higher glucose levels in cattle with high circulating adiponectin when compared to cattle with normal adiponectin levels. As mentioned above, we observed low adiponectin levels in ketotic cows. Glucose levels are also usually decreased in cows suffering from ketosis (21). As twothirds of the cows selected for the study were ketotic in the presented study, we concluded that the positive correlation detected between glucose and adiponectin in our study, in contrast to previous studies, could be related to the metabolic statuses of the animals used.

Yameogo et al. (31) did not find a statistically significant difference between GGT values in clinical and subclinical ketosis animals in a study conducted. Ropstad et al. (19) have reported that severe hepatic lipidosis can occur in chronic cases of ketosis. In the present study, GGT values in animals with subclinical ketosis and the control group were within normal limits, and no statistically significant difference was detected. Presumably this result may indicate that liver parenchyma is not sufficiently affected in subclinical ketosis animals, and even if no biopsy is performed, it may be considered that chronic diffuse hepatic lipidosis does not occur. In the present study, the lack of statistical significance between the values of GGT, Alb and P in the SKG and CG is in line with the results obtained in some previous studies (22).

Calcium levels were lower in ketotic groups in the presented study. Ketosis and calcium metabolism are in a relationship that directly affect each other. In general, hypocalcemia may be shaped at varying degrees in the animals with ketosis. Although due to metabolic acidosis at varying degrees in ketosis ionized calcium is usually normal, but a decrease in total calcium concentration also needs attention (19). In the present study, although the serum calcium levels in the two groups were within the normal limits as indicated in Table 1, there was a statistically significant difference between the subclinical, clinical ketosis group and the control group ( $\mathrm{p}<0.001)$. Similar to this finding, moderate hypocalcemia was found in subclinical and clinical ketosis cows according to a study on milk cows (5). The present study also showed that the calcium levels measured in subclinical ketosis animals were lower than the control group, the calcium binding of fatty acids resulting from lipolysis resulting in a negative energy balance and the decrease in dry matter consumption during the transitional period (19), as well as metabolic acidosis, which is more or less observed in any period of ketosis, may be due to increased calcium excretion through the urine. On the other hand, the relationship between adiponectin and blood calcium is important as a link between energy metabolism and calcium homeostasis and is widely studied, especially in human and murine models. Circulating adiponectin levels are decreased in humans with primary hyperparathyroidism $(3,28)$. In contrast to that, however, it is reported that a high-calcium diet stimulated the expression of adiponectin in mice $(24,25)$. Banga et al. (1) reported that calcium promotes the formation of high molecular weight adiponectin. Similarly, Iwabu et al. (9) reported that adiponectin increases intracelullar calcium and disruption of adiponectin receptors results in the supression of adiponectin-related intracellular calcium increase. Serum calcium levels were significantly correlated with adiponectin in the presented study. Although the exact interrelation between adiponectin and calcium is not fully elucidated, the relationship between energy metabolism and calcium homeostasis, which are the most disrupted mechanisms in postpartum dairy cows, is the topic of future studies.

In conclusion, to our knowledge this is the first study evaluating serum adiponectin levels in cows suffering ketosis. Based on the lower adiponectin levels in ketotic cows in the presented study, we conclude that animals with lower blood adiponectin levels in the early postpartum period are prone to suffer from ketosis. The 
role of adiponectin in the pathogenesis could be related to lower milk yield and better energy balance in early postpartum dairy cows with high adiponectin levels due to increased whole body tissue insulin sensitivity. However, further studies are required for elucidation of the exact relationship between the postpartum energy balance and adiponectin in dairy cattle.

\section{References}

1. Banga A., Bodles A. M., Rasouli N., Ranganathan G., Kern P. A., Owens R. J.: Calcium IS Involved in Formation of High Molecular Weight Adiponectin. Metab. Syndr. Relat. D. 2008, 6, 103-111.

2. Cebra C. K., Garry F. B., Getzy D. M., Fettman M. J.: Hepatic Lipidosis in Anorectic, Lactating Holstein Cattle: A Retrospective Study of Serum Biochemical Abnormalities. J. Vet. Intern. Med. 1997, 11, 231-237.

3. Delfinia E., Petramalaa L., Caliumia C., Cotestaa D., Tomab G., Cavallarob G., Panzironib G., Diacintia D., Minisolaa S., D'Erasmoa E., Mazzuolia G. F. Letiziaa $C$.: Circulating leptin and adiponectin levels in patients with primary hyperparathyroidism. Metabolism 2007, 56, 30-36.

4. Drackley J. K.: Biology of dairy cows during the transition period: the final frontier? J. Dairy. Sci. 1999, 82, 2259-2273.

5. Duffield T.: Subclinical ketosis in lactating dairy cattle. Vet. Clin. N. Am. Food. A. 2000, 16, 231-253.

6. Eicher R., Liesegang A., Bouchard E., Tremblay A.: Influence of concentrate feeding frequency and intrinsic factors on diurnal variations of blood metabolites in dairy cows. Proc. Am. Assoc. Bov. Pract. Rome 1998, p. 198-202.

7. Grummer R. R.: Impact of changes in organic nutrient metabolism on feeding the transition dairy cow. J. Anim. Sci. 1995, 73, 2820-2833.

8. Hayirli A.: The Role of Exogenous Insulin in the Complex of Hepatic Lipidosis and Ketosis Associated with Insulin Resistance Phenomenon in Postpartum Dairy Cattle. Vet. Res. Commun. 2006, 30, 749-774.

9. Iwabu M., Yamauchi T., Okada-Iwabu M., Sato K., Nakagawa T., Funata M., Yamaguchi M., Namiki S., Nakayama R., Tabata M., Ogata H., Kubota N., Takamoto I., Hayashi Y. K., Yamauchi N., Waki H., Fukayama M., Nishino I., Tokuyama K., Ueki K., Oike Y., Ishii S., Hirose K., Shimizu T., Touhara K.: Adiponectin and AdipoR1 regulate PGC-1 $\alpha$ and mitochondria by $\mathrm{Ca}^{2+}$ and AMPK/SIRT1. Nature 2010, 464, 1313-1319.

10. Jorritsma R., Balde E. S. J. C., Schukken Y. H., Wensing T. H., Wentink G. H. Evaluation of a milk test for detection of subclincal ketosis. Vet. Quart. 1998 $20,108-110$

11. Jorritsma R., Wensing T., Kruip T. A. M., Plam V., Noordhuizen J. P. T. M.: Metabolic changes in early lactation and impaired reproductive performance in dairy cows. Vet. Res. 2003, 34, 11-26.

12. Kabara E., Sordillo L. M., Holcombe S., Contreras G. A.: Adiponectin links adipose tissue function and monocyte inflamatory response during bovine metabolic stress. Comp. Immunol. Microb. 2013, 37, 49-58.

13. Konstantinos $K$. The role of adiponectin in regulation of metabolism in dairy cows. PhD thesis, University of Nottingham 2012.

14. Leroy J. L. M. R., Vanholder T., Van Knegsel A. T. M., Garcia-Ispierto I., Bols P. E. J.: Nutrient Prioritization in dairy cows early postpartum: mismatch between metabolism and fertility? Reprod. Domest. Anim. 2008, 43, 96-103.

15. Mecitoglu Z., Senturk S., Akgul G., Udum D., Uzabaci E., Kasap S., Catik S.: Changes in circulating adiponectin and tumour necrosis factor- $\alpha$ and their relationship with insulin resistance in periparturient dairy cows. Vet. Res. 2016, 60, 163-167.

16. NRC.: Nutrient Requirements of Beef Cattle. Seventh Edition. National Academy Press, Washington, DC 2000.

17. Ohtani Y., Takahashi T., Sato K., Ardiyanti A., Song A. H., Sato R., Onda K. Wada Y., Obara Y., Suzuki K., Hagino A., Roh S. G., Katoh K.: Changes in circulating adiponectin and metabolic hormone concantration during periparturiant and lactation periods in holstein dariy cows. Anim. Sci. J. 2012, 83 , 788-793.

18. Ospina P. A., Nydam D. V., Stokol T., Overton T. R.: Evelution of nonesterified fatty acids and beta-hydroxybutirate in transition dairy cattle in the northeastern United States: Critical thresholds for prediction of clinical diseases. J. Dairy. Sci. 2010, 93, 546-554

19. Ropstad E., Halse K., Refsdal A. O.: Variations in parameters of liver function and plasma progesterone related to underfeeding and ketosis in a dairy herd. Acta. Vet. Scand. 1999, 30, 185-197.

20. Senturk S., Cihan H., Mecitoglu Z., Catik S., Akgul G. D., Kasap S., Topal O.: Prevalence of ketosis in dairy herds in Marmara, Aegean and Mediterranean regions of Turkey. Ankara. Unıv. Vet. Fak. Derg. 2016, 63, 283-288.
21. Sevinc M., Basoglu A., Oztok I., Sandikci M., Birdane F.: The clinical-chemical parameters, serum lipoproteins and fatty infiltration of the liver in ketotic cows. Turk. J. Vet. Anim. Sci. 1998, 22, 443-447.

22. Simenson E., Halse K., Gillund P., Lutnaes B.: Ketosis treatment and milk yield in dairy cows related to milk acetoacetate levels. Acta. Vet. Scand. 1990, 31, 433-440.

23. Singh S. P., Haussler S., Heinz J. F., Saremi B., Mielenz B., Rehage J., Danicke S., Mielenz M., Sauerwein H.: Supplementation with conjugated linoleic acids extends the adiponectin deficit during early lactation in dairy cows. Gen. Comp. Endocrinol. 2014, 198, 13-21.

24. Sun X., Michael B.: Zemel Calcium and 1,25-Dihydroxyvitamin D3 Regulation of Adipokine Expression. Obesity. 2007, 15, 340-348.

25. Strang B. D., Bertics S. J., Grummer R. R., Armentano L. E.: Effect of LongChain Fatty Acids on Triglyceride Accumulation, Gluconeogenesis, and Ureagenesis in Bovine Hepatocytes. J. Dairy. Sci. 1998, 81, 728-739.

26. Veenhuizen J. J., Drackley J. K., Richard M. J., Sanderson T. P., Miller L. D. Young Metabolic Changes in Blood and Liver During Development and Early Treatment of Experimental Fatty Liver and Ketosis in Cows. J. Dairy. Sci. 1991, 74, 4238-4253.

27. Walsh R. B. J. S., Walton J. S., Kelton D. F., Leblanc S. J., Leslie K. E., Duffield T. F.: The effect of subclinical ketosis in early lactation on reproductive performance of postpartum dairy cows. J. Dairy. Sci. 2007, 90, 2788-2796.

28. Yamaguchi T., Kanazawa I., Takaoka S., Sugimoto T.: Serum calcium is positively correlated with fasting plasma glucose and insulin resistance, independent of parathyroid hormone, in male patients with type 2 diabetes mellitus. Metabolism 2011, 60, 1334-1339.

29. Yamauchi T., Kamon J., Minokoshi Y., Ito Y., Waki H., Uchida S., Yamashita S., Noda M., Kita S., Ueki K., Eto K., Akanuma Y., Froguel P., Foufelle F., Ferre P., Carling D., Kimura S., Nagai R., Kahn B. B., Kadowaki T.: Adiponectin stimulates glucose utilization and fatty-acid oxidation by activating AMP-activated protein kinase. Nature. Med. 2002, 8, 1288-1295.

30. Yamauchi T., Kamon J., Waki H., Terauchi Y., Kubota N., Hara K., Mori Y., Ide T., Murakami K., Tsuboyama-Kasaoka N., Ezaki O., Akanuma Y., Gavrilova O., Vinson C., Reitman M. L., Kagechika H., Shudo K., Yoda M., Nakano Y., Tobe K., Nagai R., Kimura S., Tomita M., Froguel P., Kadowaki T.: The fat-derived hormone adiponectin reverses insulin resistance associated with both lipoatrophy and obesity. Nature. Med. 2001, 7, 941-946.

31. Yameogo N., Oudraogo G. A., Kanyandek W. E. C., Sawadako G. J. Relationship between ketosis and dairy cows' blood metabolites in intensive production farms of the periurban area of Dakar. Trop. Anım. Health. Pro. 2008, 40, 483-490

Corresponding author: Doc. Dr. Gülșah Akgül. Deparment of Internal Medicine, Faculty of Veterinary Medicine, Siirt University, Siirt,Turkey; e-mail: gulsahvet@hotmail.com 